\title{
The Psychology of Computer Displays in the Modern Mission Control Center
}

Michael M. Granaas and Donald C. Rhea

(NASA-TM-I00451) THE PSYCHOLOGY OF COMPUTER DISPLAYS IN THE MUOFRN MISSION CONTROL

CFNTER (NASA) D $P$
CSCL OSI
N9O-22<13

unclas

$63 / 53 \quad 0279336$ 
NASA Technical Memorandum 100451

\section{The Psycology of Computer Displays in the Modern Mission Control Center}

Michael M. Granaas

University of South Dakota, Vermillion, South Dakota

Donald C. Rhea

Ames Research Center, Dryden Flight Research Facility. Edwards, California

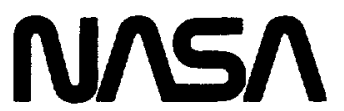

National Aeronautics and

Space Administration

Ames Research Center

Dryden Flight Research Facility

Edwards, California 93523-5000 
$-$ 


\section{SUMMARY}

Work at NASA's Westem Aeronautical Test Range (WATR) has demonstrated the need for increased consideration of psychological factors in the design of computer displays for the WATR mission control centers. These factors include color perception, memory load, and cognitive processing abilities. A review of relevant work in the human factors psychology area is provided to demonstrate the need for this awareness. The information provided should be relevant in control room settings where computerized displays are being used.

\section{NOMENCLATURE}

\section{NASA National Aeronautics and Space Administration}

STM short-term memory

WATR Westem Aeronautical Test Range

\section{INTRODUCTION}

The purpose of any real-time display, in or out of the control room setting, is to display and convey information. As computers and their display devices have entered the control room, a greater degree of flexibility in the display of information has been attained. This increased flexibility, when properly used, has the capability of improving the quality of information obtained in various flight programs, especially flight programs that involve the testing of aircraft and their components under flight conditions.

However, when these new-found capabilities are used without proper consideration for the inherent abilities of the human being as an information processor, the potential for problems arises (Wickens, 1984; Granada, 1980). These problems will generally take the form of reduced efficiency in performance and an increase in the number of errors. As a minimum, these problems cause a need for increased flight time and produce decreased quality in the data collected. At worst, additional errors could cause damage to, or destruction of, the aircraft and pilot.

To date, the author's observations at the Dryden Flight Research Facility of NASA's Ames Research Center (Ames-Dryden) suggest that the problems produce a barely noticeable decrease in overall performance, perhaps 5 percent. This minimal decrease is due primarily to the adaptive abilities of the human being. That is to say that within limits, the human is a highly adaptable animal. However, when pushed beyond those limits, the ability of the human to adapt deteriorates rapidly.

Current levels of information being displayed are starting to crowd the limits of the human's ability to adapt. As aircraft and test programs become more complex, and more information is needed by the human users of the information display units, performance will begin to diminish rapidly.

However, many of the potential problems can be offset by using better display designs to assist the user in the acquisition and processing of information. This paper is intended as an introductory overview of some of the basic psychological issues that are important in the design of computerized displays for the control room.

\section{COLOR PERCEPTION}

With the increased availability and use of color displays, how people perceive color is an important concern. A number of factors need to be considered in the selection of colors for use in a given display.

The first of these factors has to do with the appropriate use of color. Unless color is used to transfer information to the user, it has no purpose on the display. Color that is used to make a display more attractive serves only as a potential 
distractor to the user (Durrett and Trezona, 1982; Mitchell and others, 1982; Shneiderman, 1987). In addition, if color is used in some portions of the display as a redundant information carrier (for example, tum a portion of the display from green to yellow to red to indicate increasing levels of danger in some values), nonfunctional color use elsewhere on the display may have the effect of causing the user to screen out color information, even when it is important.

The second of these factors has to do with the choice of primary and secondary colors. Primary colors will generally be more salient than secondary colors. Thus, in a display that mixes primary and secondary colors, the primaries will draw the user's attention away from information being displayed in secondary colors. In a display that needs only three or four colors, the primaries are the best choice since they will be most easily distinguishable.

The choice of exactly which colors to use also depends on two other factors: the first is cultural stereotypes (Shneiderman, 1987), and the second is discemability. In the United States and other westem countries, red, yellow, and sometimes orange are colors generally used to convey a cautionary or waming message. In displays where such messages are appropriate, the display of routine information (for example, chart labels) in these colors could cause confusion and a lack of vigilance on the part of the user.

The problem of discemability becomes an issue when choosing multiple colors for a display (Weitzman, 1985). As previously mentioned, primaries will draw attention away from secondaries causing a less effective transmission of information to the user of information displayed in those colors. Different shades of the same color (for example, aquamarine and light blue) may be perfectly discemable when compared side by side, but when separated across a display containing one or more other colors, they are no longer distinguishable, and the information they are meant to convey is lost. And finally, similar secondaries are more difficult to distinguish from one another in the presence of primary colors.

Thus, the selection of colors is an important matter where the conveyance of information is the goal. Yet, display designers often select colors without sufficient consideration of how users are going to "see" the colors. Thus, a number of problems arise.

If visual testing of users is not possible, red-green or yellow-blue color combinations will cease to be effective for color blind users (Weitzman, 1985). This reinforces the idea that color should be used as an additional, redundant message channel in most cases. This is especially true in alphanumeric displays where color coding should be exclusively a redundant code.

\section{MEMORY LOAD}

A major area of concem in the real-time environment of the control room is that of short-term memory (STM). Short-term or working memory is generally considered to be a limited capacity store available for relatively short duration (20 to $30 \mathrm{sec}$ without rehearsing) (Bransford, 1979; Neisser, 1976). The capacity of STM is generally acknowledged to be $7 \pm 2$ items (Miller, 1956). A convenient way to think about STM, for the purposes of this work, is as the attentional capacity available. The notion of attentional capacity is not strictly correct, but it serves well. Due to its limited capacity, STM is quite easy to overload in the real-time environment of a mission control center.

There are a number of ways in which STM overload might be induced in the control room setting. If the user is required to compare values from different portions of the display, one set of the values to be compared needs to be committed to STM for later comparison to the other set (for example, desired parameter values and actual parameter values). This may take up as many as five of the $7 \pm 2$ slots available in STM. Add to this the slots taken by the attentional capacity demanded by other tasks, and it is easy to see that STM can easily be overloaded. 


\section{COGNITIVE PROCESSING ABILITIES}

The human user in a computer-person system can be viewed as an active processor of information (Granada, 1980). As an active processor of information, the human has certain expectations and abilities. Information that violates the user's expectations or abilities will cause the user to become an inefficient processor of the information presented (Bransford, 1979; Neisser, 1976).

Psychological problems that might arise as a result of incomplete consideration of the user's processing abilities include parameter-command abbreviations and icons that are more cryptic than informative, or display formats that interfere with understanding rather than enhance it.

Cryptic abbreviations and icons are often difficult to learn and therefore slow the user in the initial, learning stages of use. Less frequently used commands and abbreviations might never be learned, and therefore they will continue to slow the user whenever they are needed by requiring the user to perform some sort of a look-up to deternine which command is needed in a given circumstance.

An example of a display format that would interfere with information processing would be one that places information that needs to be integrated in different areas of the display. Another example would be a display that contains distracting information (for example, unnecessary parameters), or features (such as blinking characters). In both cases, the needed information can be obtained, but it requires additional cognitive processing effort on the part of the user.

\section{CONCLUDING REMARKS}

In this paper, we provide only a brief introduction to the problems that can arise when the psychological abilities and limits of the user are not taken into account. It should be remembered that just as the physical limits of the user must be considered when designing a human-machine system, so too the psychological limits of the user must be considered. Otherwise, systems that are unnecessarily difficult to use or error prone will oftentimes be developed.

\section{REFERENCES}

Bransford, J.D., Human Cognition: Learning, Understanding, and Remembering, Wadsworth Publishing Co., Belmont, California, 1979.

Durrett, J., and J. Trezona, "How to Use Color Displays Effectively," BYTE, Apr. 1982, pp. 50-53.

Granada, R.E., "Man/Machine Design Guidclines for the Use of Screen Display Terminals," Proceedings of the Human Factors Society Meeting, Los Angeles, Human Factors Society, Oct. 1980, pp. 90-92.

Miller, G.A. "The Magical Number Seven, Plus or Minus Two: Some Limitations on our Capacity to Process Information," Psychological Review, vol. 63, no. 2, 1956, pp. 81-97.

Mitchcll, C.M., L.J. Stewart, A.K. Bocast, and E.D. Murphy, Human Factors Aspects of Control Room Design: Guidelines and Annotated Bibliography, NASA TM-84942, 1982.

Neisser, Ulric, Cognition and Reality: Principles and Implications of Cognitive Psychology, W.H. Freeman and Co., San Francisco, 1976.

Shneiderman, Ben, Designing the User Interface: Strategies for Effective Human-Computer Interaction, AddisonWesley Publishing Co., Reading, Massachusctts, 1987.

Wickens, C.D., Engineering Psychology and Human Performance, Charles E. Merrill Publishing Co., Columbus, Ohio, 1984.

Weitzman, D.O., "Color Coding Re-Viewed," Proceedings of the Human Factors Society, Santa Monica, California, 1985, pp. 1079-1083. 


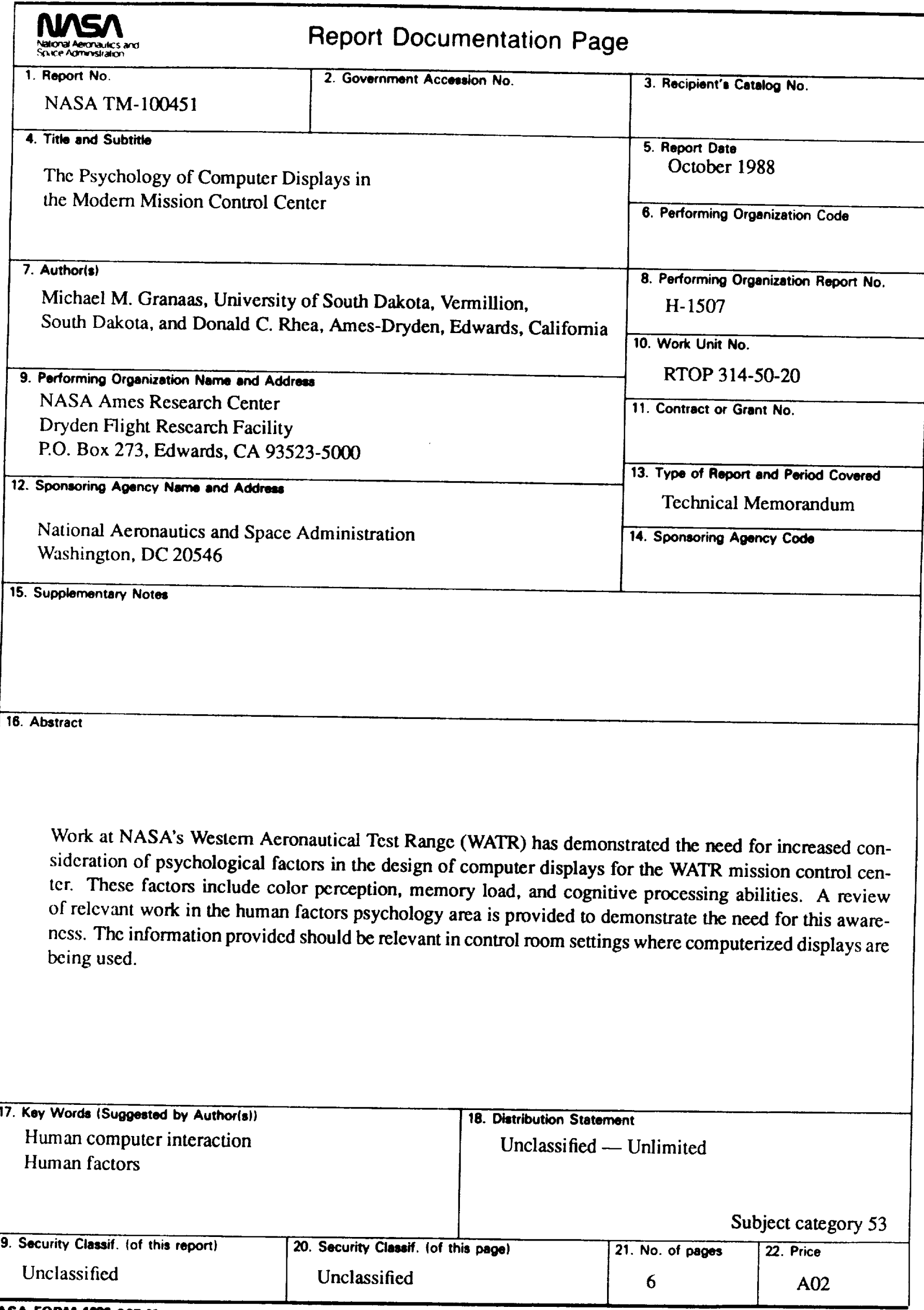

